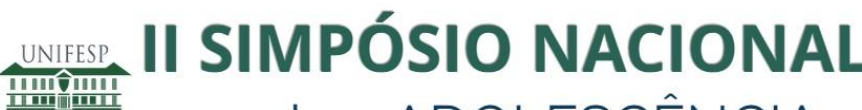 sobre ADOLESCÊNCIA: Vulnerabilidades, Protagonismos e Desafios
}

\section{O olhar do atendimento á portadores de hiv, pelo enfermeiro em uma clínica da família na zona oeste do Rio de Janeiro}

\author{
Maria Regina Bernardo Silva \\ Universidade Estácio de Sá \\ Gabriella de Carvalho Miranda \\ Universidade Castelo Branco \\ E-mail: gmiranda06@hotmail.com \\ Andressa Pereira Costa \\ Universidade Castelo Branco
}

\begin{abstract}
Como citar:
SILVA, Maria Regina Bernardo; MIRANDA, Gabriella de Carvalho; COSTA, Andressa Pereira. O olhar do atendimento á portadores de hiv, pelo enfermeiro em uma clínica da família na zona oeste do Rio de Janeiro. In: II SIMPÓSIO NACIONAL SOBRE ADOLESCÊNCIA: VULNERABILIDADE, PROTAGONISMOS E

DESAFIOS, 2. 2016, São Paulo. Anais...[S.I]: 2016. p. 55-56.

DOI: http://dx.doi.org/10.22388/2525-5894.2016.035
\end{abstract}

Introdução: o estudo apresenta o relato de enfermeiros que atuam numa clínica da família e mostra como tem ocorrido a prevenção, o diagnóstico e o acompanhamento dos pacientes soropositivos. Nos últimos cinco anos o Brasil tem registrado uma média de 39,7 mil casos de AIDS. Tendo na Região Sudeste uma maior incidência de casos registrados pelo sistema de informação de agravos de notificações (1).

Objetivo: relatar o acompanhamento dos usuários soropositivos fornecido pela enfermeiro (a) na estratégia saúde da família (ESF);

Metodologia: trata-se de uma pesquisa exploratória e qualitativa aplicada á (8) enfermeiros, de uma unidade básica de saúde no Rio de Janeiro que atualmente acompanha 49 pacientes portadores de HIV, autorizado pelo comitê smsrj 54460516.8.0000.5279 Resultados: 75\% dos entrevistados são do sexo feminino, jovens e 87,5\% trabalham cerca de 1 á 3 anos na ESF destes 50\% fizeram especialização em saúde da família.Todos informaram que fazem o aconselhamento,no entanto,apenas $50 \%$ realizam o aconselhamento pós teste rápido e com o resultado negativo o enfermeiro orienta, pode solicitar exames e pode transcrever a medicação." Entre os fatores que facilitam o acompanhamento o vínculo estabelecido pela equipe multidisciplinar" e a participação da família Entre as barreiras encontradas para a não realização do acompanhamento o medo e a quebra de sigilo foram ressaltados. Mas alguns responderam não existir e que todos usuários soropositivos passam pela clínica.Após a realização do teste rápido sendo o resultado positivo o atendimento é em conjunto com outros profissionais e $62,5 \%$ dos entrevistados salientaram que as consultas são feitas mensais. 
Conclusão: observa-se na prática, que são poucas as ações de acolhimento e aconselhamento. Podemos atribuir a esse fato o grande fluxo de atendimento que esses profissionais realizam nas unidades básicas de saúde, tornando necessário fragmentar algumas ações assistenciais para atender a demanda da área de atendimento. $\mathrm{O}$ vínculo com o usuário, foi o fator facilitador mais citado pelos enfermeiros, as barreiras encontradas foram: o medo da quebra do sigilo sobre o diagnóstico, a presença do agente comunitário de saúde nas residências e o tabu. Sugestão: Realizar mais ações educativas envolvendo os profissionais multidisciplinares no decorrer do ano, estimulando a participação da comunidade nas ações preventivas. $\mathrm{E}$ implementar mais capacitações voltadas aos profissionais na assistência de pacientes HIV.

(Universidade Castelo Branco)

Palavras-Chave: Hiv. Enfermeiro. Assistência. Clínica. Aconselhamento.

\section{Referências}

BRASIL. Ministério da Saúde. Boletim Epidemiológico HIV AIDS. Brasília, 2014. Ano III- $\mathrm{n}^{\circ} 0127^{\circ}$ a $52^{\circ}$ semanas epidemiológicas- julho a dezembro de $201301^{\circ}$ a $26^{\circ}$ semanas epidemiológicas - janeiro a junho de 2014. ISSN: 1517-1159. p.11. 